\title{
EL INTÉRPRETE \\ FELIPILLO ENTRE INCAS \\ Y CONQUISTADORES
}

Jochen Plötz

Universidad de Ciencias Aplicadas de Fráncfort del Meno, Alemania

http://dx.doi.org/10.18778/8220-201-4.25

\section{Resumen}

El artículo busca contribuir a la investigación de los papeles atribuidos al mediador lingüístico y, por extensión, transcultural, como son los de traidor, el que no dice todo lo que sabe persiguiendo intereses propios, y otros más. Se establecen unas pautas que caracterizan las situaciones comunicativas conflictivas a lo largo de la historia. Asimismo, se propone una línea de investigación traductológica, interesada en la realización de la mediación lingüística misma y sus circunstancias, como aporte a la historia de la traducción. El caso al que se aplica este programa en el presente artículo es el enfrentamiento entre los incas y los conquistadores europeos en el Perú, en el cual actuaron unos intérpretes indígenas sobre los que se ha producido y se sigue produciendo toda una gama de proyecciones y atribuciones.

Palabras clave: Historia de la traducción, representaciones en historiografía y literatura del intérprete entre partes en conflicto abierto, traducción y poder, la mediación lingüística en la conquista del Perú.

\section{1.}

\section{Presentación}

Este artículo es un resultado de mi investigación sobre la mediación lingüística entre los incas y los conquistadores europeos que, probablemente, fue el primer contacto entre los idiomas quechua 
(actualmente con 10 millones de hablantes en América y Europa) y español, grandes lenguas hegemónicas en condiciones de imponerse y de avasallar, como dice William Ospina (Ospina, 2013: 40). Busca abordar dos principales líneas temáticas: las tensiones entre lenguas dominantes y lenguas vernáculas, y la historia de la traducción como oficio intercultural.

Mi tema es el papel del indio tallán Felipillo, quien -junto a unos colegas igualmente provenientes de las zonas ribereñas pacíficas del norte del subcontinente- llegó a interpretar en los primeros encuentros entre los incas y los conquistadores europeos. Haré una muy breve introducción al fondo histórico, luego viene un repaso por las intervenciones de los intérpretes. Algunos de los reflejos posteriores de las mismas constituyen la tercera parte antes de unas breves conclusiones y perspectivas hacia futuras líneas de investigación.

Los encuentros de estas lenguas hegemónicas en el primer tercio del siglo XVI en el norte del subcontinente cumplen de manera ejemplar con las pautas de los escenarios que caracterizan la historia de la traducción: Los traductores tenían y tienen que prestar sus servicios entre representantes de partes bélicamente opuestas y enemistadas. Fueron, más bien, encontronazos donde cada participante corría el riesgo de muerte. (Hablo de 'los traductores' aunque esté consciente de la tergiversación causada por el idioma, pues la mayoría de quienes ejercen dicha profesión son mujeres).

Las crónicas son las principales fuentes de esta investigación. Han sido revisadas una y otra vez por estudiosos como Raúl Porras Barrenechea o el mismo William Prescott, por solo mencionar dos investigadores pioneros; sin embargo, muy pocas veces lo han sido a partir del interés en la labor mediática de los intérpretes. Mientras que hay una investigación amplia sobre la indígena mediadora lingüística e intercultural por excelencia, Malinalli o Malintzin, doña Marina o La Malinche cuya personalidad, además, inspiró a toda una gama de creaciones artísticas, reina escasez de estudios sobre sus colegas contemporáneos. Últimamente, se nota un interés creciente en el tema, como corroboran p. ej. trabajos de Sabine Fritz o de Hanna Lena Geiger sobre el contacto 
de los conquistadores con el pueblo taíno que había puesto de relieve hace décadas ya el gran personaje de la interpretación oral simultánea, Mariano García Landa al destacar el intérprete español-taíno Cristóbal Rodríguez.

\section{2.}

\section{Breve introducción al fondo histórico}

La razón de fondo de la tan rápida conquista y del derrocamiento del imperio incaico consistió en la profunda crisis que hace unas décadas este imperio venía viviendo, razón que era vigente también por los sucesos paralelos de México. Dicha crisis había conducido a la guerra fratricida entre los hermanos Atahuallpa, el quiteño, y Huáscar, el cuzqueño. Los conquistadores atravesaban tierras, conquistadas a su vez poco antes por Atahuallpa desde el norte, y siendo enemigos del usurpador Atahuallpa, podían aprovecharse de la actitud en su contra arraigada en algunos sectores de la población local. Esta inédita guerra fratricida, claro está, era el síntoma del desmoronamiento de valores y estructuras del imperio en el que se entremezclaron las tradicionales contradicciones entre la población del norte y del centro y sur al igual de aquellas contradicciones entre los pueblos periféricos y la gente residente en los inmensamente ricos centros Cuzco y Quito con, según Tzvetan Todorov, la imparable pérdida de la capacidad de hegemonizar la comunicación y de controlar la interpretación de los signos. Las dudas de que los foráneos fueran dioses o semidioses o seres humanos, que le acompañaron a Atahuallpa hasta su muerte, no eran si no la expresión más nítida de la incertidumbre con creces.

El reclutamiento de los intérpretes, bien fuera forzoso o no, lo hicieron los españoles de manera sistemática ${ }^{1}$. Esto quiere de-

1 El pedido o el robo de jóvenes nativos para el servicio interlingüístico lo mencionan todas las crónicas. Aquí solo dos ejemplos, para dar una noción de diferencia entre los relatos. El texto iconográfico 
cir que tomaron jóvenes ya durante sus primeras 'expediciones al sur', y durante los primeros contactos con los nativos poco después de atracar en las costas pacíficas. Estas regiones, entre Atacames y Piura, eran periféricas en el imperio y fueron pobladas por los tallanes o yungas ${ }^{2}$. La procedencia de este pueblo, que mira atrás hacia orígenes míticos, no permite de por sí la conclusión de que los jóvenes intérpretes fueran partidarios de Huáscar, pero no cabe la menor duda de que repercutió en su actitud tanto frente a la cúpula incaica como a la suntuosidad cuzqueña. Para la comprensión de lo complejo de los acontecimientos siguientes es muy importante el hecho de que estos jóvenes, a partir de su reclutamiento, vivían en contacto estrecho y continuo con los conquistadores. Como en la conquista de México, también en la del Perú fueron los hablantes de los idiomas aborígenes quienes aprendieron primero la lengua del otro.

Felipillo les sirvió a los españoles de asesor transcultural y de intérprete en todos los diálogos que se producían a lo largo de la conquista a comienzos de los años treinta del siglo XVI, hasta el enfrentamiento decisivo y la farsa del tribunal en contra de Atahuallpa. De vez en cuando, se mencionan a sus colegas Martinillo, Francisquillo y Juan.

de Felipe Guamán Poma de Alaya menciona a Felipillo por primera vez así: "Con esta nueva y codicia y publicamiento de oro y plata se hicieron gente, éstos llevaron hurtado a un indio Guancabilca, después se llamó Felipe y trajeron por su lengua a la conquista de este reino..." (Guamán Poma de Alaya, 1980: I 269). Pedro Cieza de León, quien en todo el enfoque de su relato pone énfasis en el conflicto entre Incas y los pueblos periféricos, lo narra así: "le dieron un muchacho a quien llamaron Felipe, $y$ a otro que pusieron don Martin. [...] De aquí navegaron, y en Puerto Viejo salieron muchas balsas con mantenimientos, mostrando todos mucha alegría con ver y hablar con los españoles; y le dieron otro muchacho, a quien pusieron por nombre Juan" (Cieza de León, 1984: 252 y ss.). Véase, respecto de la diferencia en cuanto al lugar de origen de Felipillo, la nota de pie nro. 4.

2 'Yunga' en idioma quechua, significa 'región de temperatura ardiente’ y, por extensión, 'cosa y/o persona relativa a estas regiones'. 
En 1529, Francisco Pizarro lo llevó consigo a España cuando, después de tantos fracasos, emprendió un viaje a la metrópoli con el fin de pedir más recursos para la empresa conquistadora y más garantías de beneficios personales ante la Corona, además de conseguir más compañeros confiables a los cuales buscó, sobre todo, entre su parentesco; una decisión que surtiría efectos más bien opuestos a sus expectativas. La estancia de Felipillo en la península es una de las grandes lagunas de la investigación. Sería muy interesante, claro está, saber de las experiencias de Felipillo y de sus compañeros a lo largo de estos casi dos años.

Felipillo y unos colegas suyos hacían parte de la tripulación de la flota que, en 1531, zarpó desde Panamá rumbo al sur. Es mencionado por todos los cronistas como traductor en los encuentros entre indios y conquistadores que se produjeron a partir de la llegada de estos en la isla Puná, cerca de Tumbes, en 1532. Salvo Miguel de Estete, que también habla de 'Martín lengua', todos los demás cronistas lo mencionan únicamente a él durante la escena clave en la plaza grande de Cajamarca, que se revelaría como emboscada de los españoles y conduciría a la detención de Atahuallpa. Durante el cautiverio del emperador inca, Felipillo es consultado repetidamente tanto por los conquistadores como por el estado mayor incaico. Varios cronistas cuentan de una relación amorosa o forzada entre él y Sancta, una de las concubinas de Atahuallpa. Se pierden los rasgos del curso de su vida después del asesinato de Atahuallpa. Últimamente, se ha planteado una teoría controvertida de que el envenenamiento de Atahuallpa fuera ordenado por Francisco Pizarro y llevado a cabo por el mismo Felipillo ${ }^{3}$. Los cronistas Juan de Betanzos y Alonso Borregán mencionan la ejecución de Felipillo como castigo por el intento de una insurrección de los indios dentro de la expedición hacia Chile, emprendida por Diego de Almagro.

3 Esta teoría se sustenta en la tesis de que el verdadero autor de la 'Nueva coronica y buen gobierno' no es Felipe Guamán Poma de Alaya, sino el jesuita Blas Valera, quien, al referirse a una carta de Francisco de Chaves del agosto de 1533, narra este episodio en un aparte nuevo del texto cuya autenticidad es controvertida. Véanse las investigaciones en curso: Laurencich Minelli (2000, 2002). 
La serie de enfrentamientos en los que las partes opuestas hablaron y se sirvieron del intérprete Felipillo se desarrolló en medio del desconocimiento de los motivos, los planes y la verdadera fuerza de la otra. Cada conversación acaeció bajo la amenaza de que, de repente, se tornaría en una contienda con peligro de muerte. En este ambiente, los intérpretes tenían que prestar servicio de traducción consecutiva y a veces, acorde a las necesidades, también simultánea.

\section{3. \\ Repaso por las intervenciones de los intérpretes}

Ya el primer encuentro, en el que le tocó a Felipillo traducir durante el enfrentamiento con el cacique Tumbalá en la costa de Tumbes, confirmaba la alta peligrosidad de las circunstancias de su trabajo. Francisco Pizarro aprovechó la discordia entre grupos de la población local, posiblemente a su vez procedente de la guerra fratricida para continuar la conquista subiendo los Andes hacia los centros incaicos y proseguir su blanco, el legendario oro.

La situación comunicativa a menudo se agravó por ofensas personales, demostraciones de soberbia y arrogancia; por otra parte, se dificultó aún más para los intérpretes por el protocolo oficial y representativo que, en cada momento, aclarase el altísimo y, respectivamente, supremo rango que les correspondía a las autoridades de sendos lados.

Probablemente, la primera ocasión en que unos enviados especiales españoles se encararon con Atahuallpa, se dio el día anterior al enfrentamiento cumbre en uno de los refugios mayores cerca de Cajamarca, donde el Inca solía morar para descanso y recuperación durante batallas. Todos los cronistas reportan la escena poniendo énfasis en diferentes aspectos de la misma. El objetivo de las dos delegaciones bajo los mandos de Fernando Pizarro, Hernando Pizarro y Hernando de Soto consistía en 
invitar a Atahuallpa a reunirse con el 'gobernador' en Cajamarca. El episodio se caracteriza por la paradigmática oscilación entre un protocolo oficial que las autoridades procuraron mantener y -al margen del mismo - el intercambio de ofensas, atrevimientos e intimidaciones. Es famosa la demostración equina que motivó a los cronistas a una prosa muy decorativa. Atahuallpa no hizo mudanza alguna aunque el caballo le resollara en la cara e hiciera mover las cuerdas de su borla, sino que exigió que se le devolviese todo el oro, plata y otras cosas que habían tomado a sus vasallos y amigos y se fuese luego de su tierra. En la versión de algunos, luego mandó matar a muchos de los que huyeron de la carrera y vecindad de los caballos. Antes, se invitó a brindar con chicha de cálices de oro y plata el que, de acuerdo a algunos, fue aceptado, mas rechazado según otros. Diego de Trujillo, un posible cronista testigo, reporta que Hernando Pizarro mandó a los traductores asomarse y traducir: 'Decidle al perro que salga luego'. Con tal ofensa, desde luego, el soberbio extremeño ya no se dirigía al supremo mandatario, sino a una persona con la que había peleado en días anteriores y a la que acababa de reconocer nuevamente en el aposento. No solo cambian los idiomas sino también los registros del lenguaje siendo un medio de intercambio de informaciones para convertirse, de un momento al otro, en un modo de amedrentar y ofender.

Es apenas imaginable el dramatismo que cundía en la plaza mayor de Cajamarca aquel mediodía, cuando finalmente se produjo el enfrentamiento entre Felipillo, Atahuallpa (acompañado por sus confiables) y Vicente Valverde, cuyos afiliados se mantuvieron en la retaguardia en la que habían convertido las casas colindantes de la plaza, prestadas para su hospedaje por Atahuallpa. Mientras que el fraile dominico insistió en pronunciar un sermón de corte misionero y apodíctico, Atahuallpa quería, como ya lo había hecho el día anterior, aprovechar la oportunidad para exigir la devolución de personas secuestradas y bienes robados, así como el escarmiento de los violadores y victimarios. El fraile no quiso entrar en tal debate, achacó todas estas crueldades a la guerra fratricida e intentó destacar su insistencia en la conversión, elevando la Biblia abierta y mostrándosela a Atahuallpa; otros hablan del 
breviario que quiso que Atahuallpa lo abriese. Este, de ninguna manera, se mostró impresionado y alegaba que él mismo era hijo del sol y así del único Dios supremo, es decir, cuestionó totalmente, y con argumentos apropiados, el reclamo de la posesión de la verdad exclusiva por parte de su contrincante. Hay diferentes descripciones de la escena original de la conquista del Perú con relación a lo que pasó luego con el libro sagrado, yendo de la mera demostración por Atahuallpa de no ser convencido, hasta un golpe suyo al brazo del otro extendido con el libro, que hizo que este se cayera. Todos coinciden, en cambio, que el rechazo contundente del libro sagrado por parte del Inca supremo motivó a Vicente Valverde, ya enfurecido por la intransigente incredulidad de su opositor, a dar a Francisco Pizarro la seña del ataque acordada, el tradicional grito guerrero de los españoles: 'Santiago'.

Parece que Felipillo, al darse cuenta de que Atahuallpa se había negado a comprender sus traducciones del mensaje del fraile Valverde de la trinidad divina y de la exhortación a reconocerla y a subordinársele, quiso hacer uso de adaptaciones derivadas de la cultura destinataria. Dijo que el fraile y el marqués, ambos hijos del sol, fueron enviados por el Dios Sol y que, por tanto, Atahuallpa debía obedecerles. Continuó diciendo que la 'pintura' de toda esta religión, la única verdadera, se encontraba en el famoso libro simbólico. No sorprende que ni dichos intentos ni el libro con sus monótonos renglones lograran convencer a un Atahuallpa cargado con toda la responsabilidad y la pesadumbre de ser el hijo del sol. Dados estos posicionamientos, a Felipillo le correspondía la transformación intergenérica entre todo el significado del libro y de la santa escritura para la cosmovisión representada por Valverde y la oralidad y autoridad del representante e hijo del Dios Sol.

Otras versiones resaltan más la amplia respuesta de Atahuallpa reduciendo la exposición de Valverde a que este rutinariamente "dióle noticia acerca del dios de la cristiandad y terminó invitándolo a la abjuración y al vasallaje. Díjole por boca de Felipillo el indio lenguaraz. [...] Fingiendo querer persuadirle, dióle Valverde al Inca su Biblia o Breviario, conjurándolo a reconocer en el libro la escritura de Dios." (Porras Barrenechea, 1937: 86) 


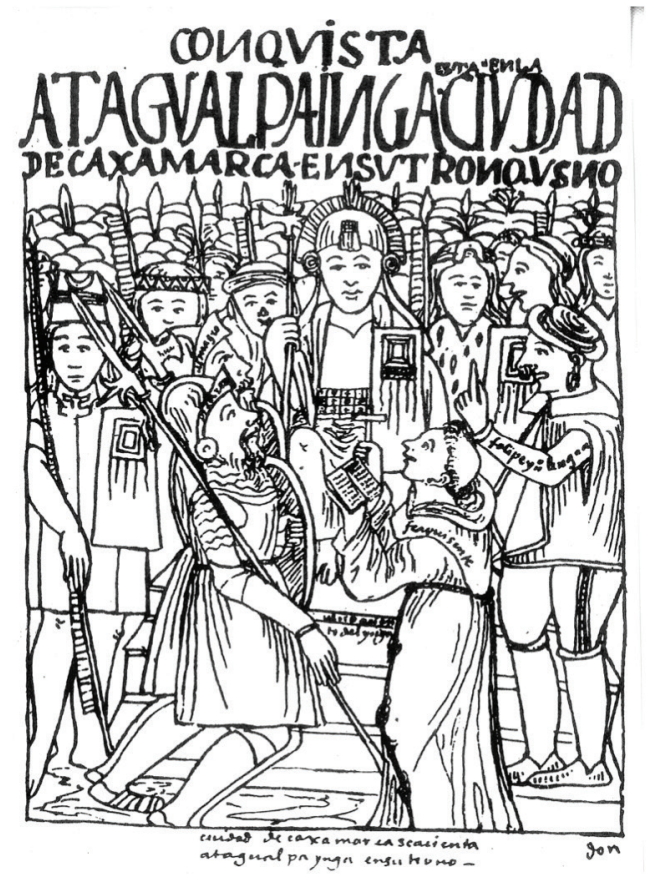

Figura 1. "Conquista. Atagualpa Inga está en la ciudad de Caxamarca en su tronousno. Almagro. Pizarro. Fray Vicente. Felipe, indio lengua. Usno, asiento del Inga. Ciudad de Caxamarca se asienta Atagualpa Inga en su trono" (Guamán Poma de Ayala, 1980: | 278).

\section{4. Reflejos posteriores de las intervenciones de los intérpretes}

Mientras que la gran mayoría de los cronistas, entre ellos los muy pocos auténticos testigos, no hace sino mencionar a los intérpretes así como la presencia y los logros y fallos de la labor de ellos fuesen lo más rutinario, pues no desempeñan un papel importante en su interés de elaborar textos apologéticos y panegíricos, aquellos cronistas que orgullosamente se distinguen por su conocimiento 
y comprensión de la cultura y la lengua de los indios, sí prestan mayor atención a los intérpretes.

Todos los cronistas denominan 'lenguas', 'farautes' o 'lenguaraces' a los traductores. Vale señalar que la denominación de 'lenguaraz', a lo largo de su uso calificador de personas, vivía el desarrollo del original sentido políglota hasta señalar al atrevido e irrespetuoso. El hecho de que todos mencionen a 'las lenguas' cuando lleguen al clímax de sus narraciones, corrobora el papel fundamental de Felipillo y sus colegas en las escenas descritas. Coinciden en que, por lo general, los intérpretes lograron hacer bien su tarea de conseguir comprensión. Hay algunas menciones de la fluidez con que hablaron la lengua de los españoles y hay varios informes sobre situaciones en las que se identificó la razón del fracaso de la comprensión explícitamente en la falta de la presencia de 'lenguas'. El desempeño del papel del traductor, es decir, ser a la vez emisor y receptor en un intercambio de discursos pertenecientes a sistemas profundamente ajenos, le tocó a Felipillo entre frentes contrariamente opuestos que se sirvieron de todos los recursos retóricos de ambigüedad y falsedad, cambiando continuamente los registros lingüísticos, de acuerdo con sus respectivos intereses de establecer un recíproco reconocimiento de autoridad, de amedrentar y hasta de ofender al otro.

Pedro Cieza de León y Juan de Betanzos fueron dos de los más famosos cronistas que adoptaron una distancia de la voluntad destructiva y de la codicia que divisaron en sus compatriotas. Comparten la comprensión de la otra cultura con los intérpretes, y a la vez compiten con ellos. Atribuyen una actitud intrigante a los intérpretes, explícitamente a Felipillo, achacándoles el interés en atizar el enfrentamiento bélico y en debilitar la otra facción, liderada por Hernando Pizarro entre otros, quien no fue partidario de la ejecución de Atahuallpa, sino que propuso llevarlo a la metrópoli europea o, por lo menos, llevarlo a Cuzco con el fin de proceder a un interrogatorio según lo estipulaban las leyes de la Corona. Fue, sobre todo, fray Vicente Valverde, fanatizado en su mentalidad de cruzada, como lo describió Tzvetan Todorov, quien empujó a Francisco Pizarro a optar para la vía de eliminación del 
enemigo, a sabiendas que era fácil manipular a este último, debido a su baja capacidad de discernimiento y su analfabetismo.

Un papel particular desempeña el Inca Garcilaso de la Vega, nacido en 1539 como hijo de una princesa inca y un oficial español. 'El testigo de haber oído', como al orgulloso mestizo de dos culturas le gustaba presentarse a sus lectores, sostuvo que el lenguaje de los intérpretes era aquel de 'los soldados bisoños', debido a su contacto permanente con ellos. Además, introduce un criterio histórico en su crítica del trabajo de los intérpretes, al señalar que en aquella época del primer enfrentamiento entre conquistadores e incas, y entre sendas cosmovisiones, las principales y objetivas dificultades con las que se vieron retados los intérpretes, consistían en el hecho de que todavía no existía la terminología apropiada para traducir el concepto de la trinidad al quechua.

Y si bien Felipillo, debido a su contacto con la cultura de los conquistadores, llegó a apreciar el significado que para ellos tiene la Sagrada Escritura, en cambio no logró transmitirlo a Atahuallpa, al representante supremo y más poderoso de una cultura oral, en la cual las signaturas, los quipus, servían principalmente para fines de administración y contabilidad. Con su intento de traducir el discurso valverdiano al sistema igualmente monoteísta del Dios Sol, nos remite a los conceptos de la domesticación de la palabra ajena y de la construcción de lo comparable. Para obtener una remota imagen de lo ocurrido aquel día en Cajamarca, hay que recordar el apenas ocultado desprecio del otro en el fraile y su furia al igual que lo inédito que significaba la cercanía y la suerte de igualdad con el inca que el encargo especial de Felipillo, en cierta medida, acarreó.

El artista de la gráfica, Felipe Guamán Poma de Alaya que comparte su procedencia mestiza con el Inca Garcilaso creó una obra de extraordinario valor documental Nueva Coronica y buen gobierno, detectada apenas en el año 1908 en la Biblioteca Real de Copenhague e ilustrada con 1188 dibujos de lápiz y tinta. Comentó cada una de sus imágenes de manera bilingüe, corroborando asimismo la atención especial que dedicó a la tensión conflictiva entre las dos culturas. 
En su descripción, Guamán Poma resalta tanto la soberbia en Atahuallpa y en fray Vicente Valverde (que condujo a ambas partes a su intransigencia), como, repetidamente, la difícil posición de Felipillo entre los contrincantes:

[...] y luego comenzó don Francisco Pizarro y don Diego de Almagro a decirle con la lengua Felipe indio guancavilca ${ }^{4}$, le dijo que era mensajero y embajador de un gran señor y que fuese su amigo que sólo a eso venía: respondió muy atentamente lo que decía don Francisco Pizarro y lo dice la lengua Felipe indio; responde el inga con una Majestad y dijo que será la verdad que tan lejo tierra venían por mensaje, que lo creía, que será gran señor pero no tenía que hacer amistad que también que era él gran señor en su reino.

$[\ldots]$

Atagualpa Inga fue degollado y sentenciado, y le mandó cortar la cabeza don Francisco Pizarro y le notificó con una lengua, indio Felipe, natural de Guancabilca; este dicho lengua le informó mal a don Francisco Pizarro, y los demás no les gustó la dicha sentencia, y no le dio a entender la justicia que pedía y merced Atagualpa Inga por tener enamorado de la coya, mujer legítima, y así fue causa que le matasen y le cortasen la

4 Se desconocen las fuentes que condujeron al cronista a afirmar que la región de Huancavelica ('guancavilca', 'guancabilca', 'huancabelica') correspondía al lugar de proveniencia de Felipillo. En las demás crónicas, se ubica dicha proveniencia en sitios inmediatamente costeros, desde Atacames a Paita (nombrado por varios autores), hasta más al sur. Cabe anotar que Guamán, en la parte del 'Buen gobierno', dedica un dibujo y una mención a 'Guancabilca', subrayando sus riquezas naturales y tradicionales al igual que su mal manejo y el maltrato que recientemente vivieron sus habitantes: "el cual se muere y se acaban los indios en los pueblos y quedan solas las indias y quedarán yermo. [...] y es tierra oro en polvo, oro en piedras, riquezas del mundo si lo saben gobernar irá delante. [...] el quien sabe ordenar la dejará descansar los indios, y dicha mina y riqueza que no descanse" (Guamán Poma de Ayala, 1980: II 395). 
cabeza a Atagualpa Inga y murió mártir cristianísimamente; en la ciudad de Cajamarca acabó su vida. (Guamán Poma de Ayala, 1980: I 279, 285) ${ }^{5}$.

\section{5. \\ Futuras líneas de investigación y conclusiones}

Del sinnúmero de las adaptaciones y transformaciones de las intervenciones de los intérpretes entre los incas y los europeos sólo escogí unas pocas que considero como emblemáticas.

En los mediados del siglo pasado, el gran autor colombiano Eduardo Caballero Calderón plasmó los acontecimientos como versión incaica y trágica de la leyenda del hijo perdido. En su libro 'Los hijos del sol y el pastor de puercos', publicado por primera vez en 1953, Felipillo/Francisquillo perjudicó al usurpador ilegítimo Atahuallpa porque comprendió su propio destino de ascender como intérprete entre los forasteros y su imperador como vocación que la historia le venía brindando y que debía cumplir. El mito incaico narraba que el original conflicto fraternal seguía pesando sobre la historia del pueblo y que acababa solo cuando los divinos descendientes de Viracocha Inca volvían. De nuevo, la ingenuidad humana es una de las causas de la tragedia que convirtió la bienintencionada información a los forasteros acerca de la historia propia en traición:

5 Mientras que, en algunas descripciones, la discusión cumbre se desarrolla exclusivamente entre Atahuallpa y fray Vicente Valverde, en otras no queda claro si Francisco Pizarro, Diego de Almagro y otros españoles participaron en ella; según todas las crónicas, sin embargo, está intermediada por Felipillo. La relación de Felipillo con Sancta, la coya, la 'mujer legítima' de Atahuallpa, es otro episodio ya arriba mencionado y rodeado de misterios; sobre este, ya se ofrecieron unas interpretaciones (véase Plötz, 2012: 211 y ss.), pero que aquí, por no ser el tema, solo se ha mencionado de paso. 
'Nosotros', dijo Pizarro, haciendo un guiño a los soldados que le escuchaban sentados en la playa, 'nosotros somos en realidad los hijos de Viracocha. Hemos venido a restituir el imperio del Tahuantisuyu a su legítimo dueño Huáscar. Necesitamos que tú nos ayudes en esta empresa y nos conduzcas a donde mora Atahuallpa, para apresarle y darle muerte' (Caballero Calderón, 1977: 76).

Dicho presagio, surgido del original conflicto fraternal, predecía que solo entonces, merced a su regreso, el heredado conflicto fraternal se acabaría, siendo últimamente agudizado por la infidelidad de Huayna Capac, quien no supo legar lo suficientemente claro el imperio al primogénito Huáscar o a Atahuallpa. Con su fino lenguaje, oscilante entre historiografía y leyenda (ambas en pos de comprender los avatares de la historia), Caballero Calderón entreteje las auténticas figuras del traductor, de las autoridades locales y de los conquistadores con aquellas del universo de los taquis, que constituyen el acervo de la mitología incaica.

Después del asesinato de Atahuallpa, Caballero Calderón no tiene otra salida para Francisquillo-Felipillo que aquella de "roído por el dolor y los remordimientos arrancársele los cabellos a puñados y comenzar a llorar", "mientras los soldados de Pizarro se repartían el botín y en el campamento de Atahuallpa cundía el espanto y el padre Valverde rezaba un responso por el Inca ajusticiado", o ya muerto (Caballero Calderón, 1977: 90). Llama la atención que el traductor Caballero Calderón no profundizara el tema, sino que, a su protagonista Francisquillo-Felipillo, le hace aprender y dominar el idioma extranjero con facilidad sorprendente, mientras que sí relata su viaje a España y su consiguiente fascinación por el mundo extraño.

A finales del siglo pasado, el escritor limeño Eduardo Rada escribió la serie de libros Antimemorias de Felipillo, publicada por la editorial 'Los Sobrevivientes'; en uno de sus libros, Felipillo es presentado como el fundador de toda una seductora tradición de traiciones aún no terminada, cuyos representantes actuales se dibujan así: "Los Felipillos son pues los muchos estudiantes que cada año van desde diversas partes del mundo a descubrir la 
Nueva Metrópoli. Algunos de ellos regresan a su país de origen y se convierten en los traductores oficiales de los Nuevos Conquistadores" (Rada, 1994: 14).

En el contexto de la lucha contra el avasallamiento por algunos de los pueblos situados en la periferia del imperio, en cambio, el actuar de Felipillo recupera sentido simbólico. Los Tallanes, según el historiador Reynaldo Moya Espinoza, vieron en la rivalidad de Atahuallpa y Huáscar un medio para recobrar la ansiada independencia.

Las futuras líneas de investigación, aunadas por el interés de sacar a los intérpretes de la invisibilidad, se concentrarán, sobre todo, en detectar más fuentes en toda la gama de los géneros del arte popular, donde se hallen proyecciones de la figura del intérprete que fue blanco de atribuciones de tan variada índole.

La insólita carrera de Felipillo apunta ya a otro modelo de despliegue personal, según el cual, a diferencia de la casta, de la estirpe y del estrato en la pirámide social, el aprendizaje de habilidades y el alcance de idoneidad serían reconocidos y abrirían otras desenvolturas. De ahí que habrían podido surgir unas fantasías de omnipotencia, pero también que de ahí habría podido presentárseles la oportunidad de sentir más nítidamente el ocaso del imperio incaico.

La condena del traidor le atribuye bajas intenciones, reclamando para sí mismo el conocimiento de la posición moralmente íntegra. El mismo cronista Juan de Betanzos, admirador de la cultura inca y muy sentencioso sobre Felipillo, describe la conversación entre los líderes suplentes incaicos y Felipillo, ocurrida ya durante el cautiverio de Atahuallpa y relatada también por varios otros cronistas, en la que Felipillo informa sobre sus experiencias del fin del mundo, adonde lo habían llevado, y en la que resalta su incomprensión del miedo a los barbudos, a los presuntos dioses, y a sus caballos por parte de los incas, pues ambos, barbudos y caballos, morían al igual que los incas, y él mismo lo había visto. Puede que Felipillo, al aprovechar sus conocimientos adquiridos, sopesara sencilla y oportunamente sus opciones ante el poder históricamente prevaleciente de los invasores. 
La asimetría y la enemistad de los locutores entre los que se ejerce nuestra profesión y, por ende, la incertidumbre y el peligro para quienes la ejerzan, siguen marcando una faceta esencial del ámbito de nuestro trabajo. Quienes trabajan, corren altos riesgos en países con conflictos agudos. Desde el enfoque de la historia de la traducción, ante todo hay que tener en cuenta las condiciones bajo las que hubo que ejercer la mediación, y de ahí analizar cuáles decisiones tomaron los traductores y por qué.

\section{Referencias bibliográficas}

Betanzos, J. de. (1987), Suma y narración de los Incas, Prólogo, transcripción y notas por M. del C. Martín Rubio. Estudios preliminares de D. Ramos, Madrid: Ed. Atlas

Borregán, A. (2011), La conquista de Perú, E. Stoll y M. de las N. Vázquez Núñez (eds.). Fráncfort del Meno, Madrid: Iberoamericana.

Caballero Calderón, L. E. (1977), Los hijos del sol, Con ilustraciones de Lorenzo Jaramillo, Bogotá: Carlos Valencia Eds.

Carrión, B. (2002), Atahuallpa, 10a ed. Quito: Col. Luna Tierna [1ª ed. México D. F., 1934].

Cieza de León, P. de. (1984a), La crónica del Perú. Edición, introducción y notas por M. Ballesteros Gaibrois, Madrid: Historia 16.

Cieza de León, P. de. (1984b), Obras completas I: La crónica del Perú. Las guerras civiles Peruanas, Edición crítica, notas, comentarios e índices; estudios y documentos adicionales por C. Sáenz de Santamaría, Madrid: Instituto Gonzalo Fernández de Oviedo.

Cieza de León, P. de. (1985), Obras completas III: Estudio bio-bibliográfico. Cieza de León: su persona y su obra, Índice analítico general de las obras completas de Cieza de León por C. Sáenz de Santamaría, Madrid: Instituto Gonzalo Fernández de Oviedo.

Cordero, L. (2006), Diccionario Quichua-Castellano, Castellano-Quichua, Quito: Corporación Editora Nacional.

Fritz, S. (2008), "Reclamar el derecho a hablar: el poder de la traducción en las crónicas de 
Guamán Poma de Ayala y del Inca Garcilaso de la Vega.”, en: L. R. Feierstein \& V. E. Gerling (eds.), Traducción y poder, Fráncfort del Meno, Madrid: Iberoamericana, 101-120.

Garcilaso de la Vega, Inca. (1991), Comentarios reales de los Incas, 2 vols. Edición, prólogo, índice analítico y glosario de C. Araníbar, Lima, México: Fondo de Cultura Económica.

Geiger, H. (2017), “La traducción de escenas y marcos: los múltiples procesos translatorios en la 'Relación acerca de las antigüedades de los indios' de fray Ramón Pané”, en S. Jansen, G. Müller (eds.), La traducción desde, en y hacia Latinoamérica: perspectivas literarias y lingüísticas, Fráncfort del Meno, Madrid: Iberoamericana, 36-57.

Guamán Poma de Ayala, F. (1980), Nueva coronica y buen gobierno, 2 tomos, Transcripción, prólogo, notas y cronología por F. Pease, Caracas: Biblioteca Ayacucho.

Kuzmischev, V. (1991), El imperio de los Incas. Los hijos del sol, Trad. del original ruso E. Czerniawski, Moscú: Ed. Progreso [1 $1^{\text {a }}$ ed. Moscú 1982].

Laurencich Minelli, L., "Breve reseña de los documentos Micinelli en el ámbito del Simposio 'Guamán Poma de Ayala y Blas Valera. Tradición Andina e Historia Colonial”, Espéculo, Revista de Estudios Literarios, (20), 1-8, <https://pendientedemigracion. ucm.es/info/especulo/numerol6/guaman.html>, [fecha de consulta:15.04.2011].

Laurencich Minelli, L., "Las actas del coloquio ‘Guamán Poma y Blas Valera. Tradición Andina e Historia Colonial': nuevas pistas de investigación. Una nota.", Espéculo. Revista de estudios literarios, (20), http://www.ucm.es/info/especulo/numero20/ act_colo.html, [fecha de consulta: 15.04.2011].

Moya Espinoza, R., "Los tallanes." <www.monografías.com/trabajos37/los-tallanes/los-tallanes.shtml\#ixzz35SwphcYm>, [fecha de consulta: 22.04.2011].

Oesterreicher, W. (1997), "Das Gespräch als Kriegserklärung”, en H. Wenzel (ed.),

Gespräche-Boten-Briefe: Körpergedächtnis und Schriftgedächtnis im Mittelalter, Berlín: Erich Schmidt, 296-319. 
Ospina Buitrago, W. (2013), América mestiza. El país del futuro, Bogotá: Mondadori.

Plötz, J. (2012), "Sprachmittlung des Nichtvermittelbaren. Der Dolmetscher Felipillo und seine Kollegen zwischen Inkas und spanischen Eroberern", Lebende Sprachen. Zeitschrift für interlinguale und interkulturelle Kommunikation, 57/1, 185-216.

Porras Barrenechea, R. (1937), "La conquista del Perú, llamada la Nueva Castilla”, en R. Porras Barrenechea, Las relaciones primitivas de la conquista del Perú, París: Cuadernos de historia de Perú $\mathrm{N}^{\circ} 2$.

Prescott, W. H. (1963), The Rise and the Decline of the Spanish Empire, Londres: Sidgwick and Jackson.

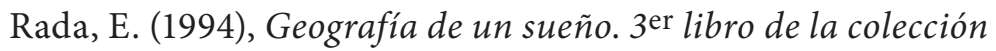
Anti-Memorias de Felipillo, Lima: Los Sobrevivientes.

Ricoeur, P. (2006), On Translation, Trad. del original francés por E. Brennan, Nueva York: Routledge [1 ${ }^{a}$ ed. París 2004: Bayard].

Ruiz de Arce, J. (2002), La Memoria de Juan Ruiz de Arce (1543). Conquista del Perú, Saberes Secretos de Caballería y Defensa del Mayorazgo, E. Stoll (ed.), Fráncfort del Meno, Madrid: Iberoamericana.

Todorov, T. (1985), Die Eroberung Amerikas. Das Problem des Anderen, Fráncfort del Meno: Suhrkamp.

Trujillo, D. (1985), "La crónica de Diego Trujillo, soldado de Pizarro en Cajamarca”, en F. López de Xerez, Verdadera relación de la conquista del Perú, Edición, introducción y notas C. Bravo Guerreira. Madrid: editorial Historia 16.

Venuti, L. (2008), The Translator's Invisibility. A History of Translation, Nueva York: Routledge. 